\title{
The future of the UK life and pensions industry
}

Received (in revised form): 7th March, 2002

\section{David Taylor}

is the Lead Principal in IBM Global Services, responsible the for Life and Pensions sector. David has spent the majority of his career in financial services including positions at Scottish Widows, TSB, Standard Life, Prime Health and as an executive consultant in the Insurance Practice of a Big Five consultancy. David has worked with a number of major insurance companies in the areas of strategy, distribution effectiveness and operational transformation.

\section{Clare Seah}

is the Lead Solutions Principal in IBM Global Services in the Life and Pensions sector. Before joining IBM Clare worked with a leading employee benefits consultancy as Group Specialist, and she is an Affiliate of the Institute of Actuaries. Clare has worked on a wide range of life and pensions engagements over the past seven years with IBM including third party administration set-up, operating model development, worksite marketing strategies and solutions delivery. Clare has consulting experience in the UK, European and US markets.

\section{Chris Cannon}

is a Senior Consultant in IBM Global Services in the Life and Pensions sector. Chris joined IBM from a leading composite insurer where he was a programme director of a major business transformation. Chris is an Affiliate of the Institute of Actuaries. Over the past five years he has worked with a number of leading financial institutions in the UK and European markets. Chris specialises in the application of technology in support of business transformation.

\section{Merlin Stone}

is the IBM Professor of Relationship Marketing at Bristol Business School, an Executive Consultant with IBM and a director of Qci Ltd, Swallow Information Systems Ltd and Viewscast Ltd. He is the author of many articles and 20 books on marketing and customer service, including 'Up Close \& Personal?', 'CRM @ Work', 'Customer Relationship Marketing', 'Successful Customer Relationship Marketing' and 'CRM in Financial Services'. He is a Founder Member of the Institute of Direct Marketing, a Fellow of the Chartered Institute of Marketing and on the editorial advisory boards of many journals. He has a first-class honours degree and doctorate in economics.

\begin{abstract}
This paper investigates the changes taking place in the UK life and pensions industry, in particular the squeeze on product providers taking place through a difficult and sometimes conflicting combination of changing demography, regulatory pressure to reduce costs and improve consumer choice, new information technology and distribution channel change. It suggests that product providers can no longer hedge their bets and must make and implement clear decisions about the role they will play in the life and pensions value chain.
\end{abstract}

Keywords: life insurance; pensions; independent financial advisors; stakeholder pensions; 1 per cent world; ageing population; advice; depolarisation; worksite marketing; multi-channel distribution; regulation

\section{David Taylor}

IBM Global Services,

76 Upper Ground, South Bank, London SE1 9PZ, UK.

Tel: +44 (0)20 7202 5029; e-mail: davidtaylor@uk.ibm. com

\section{Introduction}

The UK life and pensions industry has grown strongly in recent decades, supported by booming equity returns in the 1990 s and a relative immunity to competitive pressures. In the recent years this has been offset with increasing demands from successive governments to regulate the industry, and in the eyes of the consumer, to offer protection from 
mis-selling, maladministration and poor investment strategies in a market of reversing stock values. The euphoria of high returns in the early 1990s, with huge terminal bonuses for endowments, has been more than reversed with some Life Offices unable to meet the returns required to cover endowment based mortgages.

Lately, returns on pension funds have also declined, but here the situation is more confusing for customers, who see the UK government as partly responsible for their plight, because of the price-indexing rather than pay-indexing of the state pension, and the withdrawal of tax concessions on pension funds. This situation is particularly problematic (and, of course, mainly caused by) the rapid ageing of the UK population, meaning that the retirement market is forecast to change dramatically over the next 30 years, as shown in Table 1 . This is partly responsible for many organisations moving away from guaranteed benefits schemes to defined contribution schemes, usually resulting in lower pensions.

Results from 2001 indicate a subtle shift away from investment risk by the consumer. Individual Pension sales are down, in spite of all the press coverage of stakeholder, as independent financial advisors (IFAs) guide their customers away from Pensions and ISAs into with profits bonds and other less risky investments.

The life and pensions industry is at a crossroads - some would say in a confusing state. On the one hand, several providers are recording record new business figures and strong profits, with record growth in the numbers of IFA and new products being sold. On the other hand we have seen the advent of 1 per cent charge caps, possible depolarisation, the problems of Equitable Life, falling equity returns, interest rates at their lowest for over a generation, an
Table 1: Growth in retired population

\begin{tabular}{lll}
\hline Age group & $\mathbf{2 0 0 1}$ & $\mathbf{2 0 3 1}$ \\
\hline Working (16-64) & $36.4 \mathrm{~m}$ & $34.6 \mathrm{~m}$ \\
Retired (65+) & $10.8 \mathrm{~m}$ & $16.1 \mathrm{~m}$ \\
Retired \% of working & $29.7 \%$ & $46.5 \%$ \\
\hline
\end{tabular}

Source: Office of Population Census and Surveys population projections

increasingly enthusiastic Financial Services Authority focusing on the sector, and now Stakeholder Pensions failing to achieve the goals set by Government in terms of take-up by the less well-off.

It has been argued by Anthony Hilton, City Editor of London's Evening Standard newspaper, that just as equity markets are heading for a probably lengthy period of stagnation, the industry faces a consumerist Government which is convinced that its basic products with-profits life assurance and pension plans - perpetrate a fraud on the customer and which has imposed de facto price control by introducing stakeholder pensions backed by all the marketing muscle of government and with a ceiling of 1 per cent on charges. ${ }^{1}$ All this was before the significant market adjustment which followed the tragic events of September 11th!

This paper explores the broader impacts of these challenges on the life and pensions marketplace.

\section{Trends}

Figures 1 and 2 illustrate the current and expected future focus of providers.

Larger providers have been focusing on market share and revenue. This is due to a number of factors.

- dominant market share is needed for survival

— 'easy' pickings from Equitable Life

- operational cost levels are a real challenge for most large providers, 


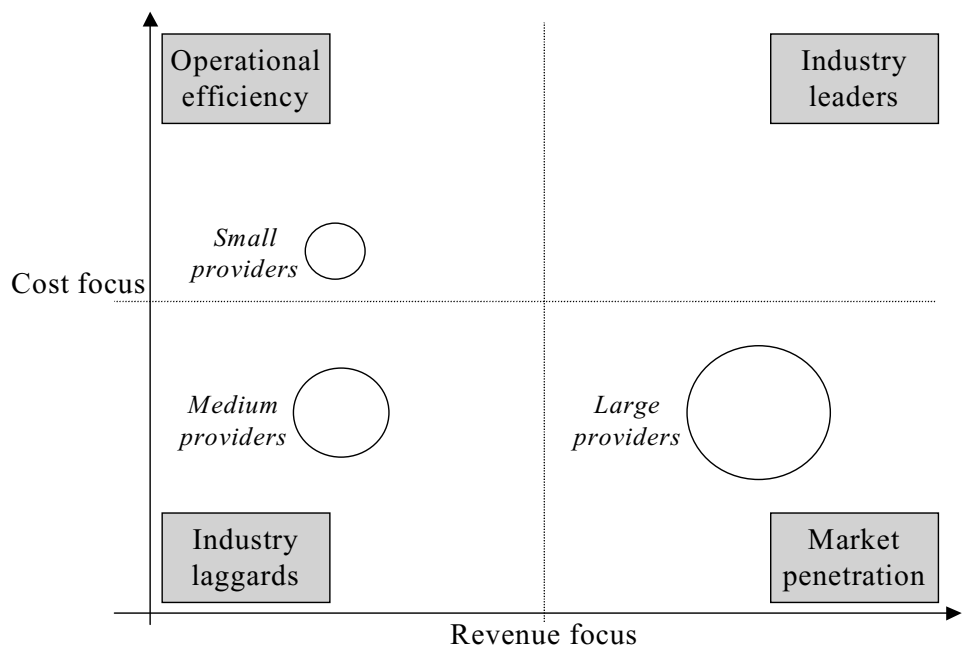

IBM Strategic Alignment Model

UK Life Offices : current effective focus

Figure 1: The current focus of Life and Pension providers

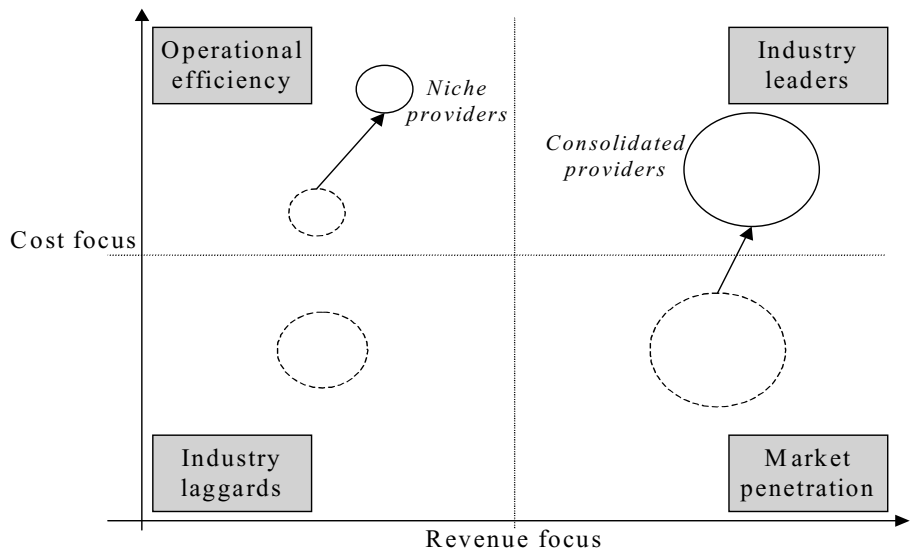

IBM Strategic Alignment Model

UK Life Offices : future focus

Figure 2: Expected future focus of providers

particularly because of Merger \& Acquisition legacies.

With the next focus for larger providers being the 1 per cent cost challenge, and with larger providers seeking to meet this partly through economies of scale, medium sized providers are unlikely to survive, while smaller providers have focused on operational effectiveness to survive as niche operations.

\section{The 1 per cent world}

Over the years, the Life Industry has grown 'fat' in the eyes of the Government and the consumer lobby eyes. It has been running at a cost level 
of around 2.6-3.0 per cent of assets in recent years. To counter this, and to encourage the democratisation of pension savings, the Government has introduced product charge caps of 1 per cent for Stakeholder Pensions and CAT-marked products. The Stakeholder model exists in other markets with similar products, such as the USA with its $401 \mathrm{k}$ product, which has been around for many years, and more recently the launch of the compulsory Superannuation Choice in Australia. In the UK compulsion has yet to raise its head, with the Government possibly waiting for a third term before pushing what is likely to be an unpopular move on the consumer.

There are some instructive lessons on compulsion from the Australian experience:

- Regulation: pensions uptake was marginal until compulsion was introduced

- Products: defined benefit schemes have declined significantly in favor of defined contribution. Retail sales declined in favour of group schemes

- Competition: large multi-employer schemes drive by industry and trades unions came into being posing a significant threat to incumbent insurers

- The difficulties in running multi-employer schemes were underestimated (eg chasing contributions from reluctant employers)

- Unbundling of administration - two large administrators dominate the Industry Fund market

- Account numbers proliferated, as every spell of work no matter how short, resulted in a new account being set up. This increased the cost base.

With or without compulsion, the introduction of Stakeholder Pensions in the UK has far reaching consequences for the industry. Many providers believe, probably rightly in the longer term, that a 1 per cent charge cap will set the benchmark for other products. Several providers have already committed to limit charges on personal pensions to 1 per cent.

Recent research (October 2001) carried out by the Finance Technology Research Centre and MORI has shown that consumers are less aware of these changes than the providers and the regulators. Consumers seeking to buy a pension or ISA were asked how aware they were of the charges applicable to Stakeholder Pensions. Figure 3 gives the results. When probed further nearly half the same consumers indicated a propensity to consider paying high fees for better returns (Figure 4), and a significant number indicated a propensity to pay more if quality advice were part of the overall proposition (see Figure 5). Additional research, also carried out by FTRC and MORI in the summer of 2001, indicated that less well off consumers would seek higher returns from an investment product, whereas better off consumers were more interested in appropriateness (see Figure 6). This research suggests that providers will need to vary offers by segment. The real challenge is that for consumers targeted for Stakeholder Pensions, the expectation is that quality means higher returns, which the consumer thinks they can obtain by paying for!

The main impact of the 1 per cent world on providers will be the big reduction in costs required to make products such as Stakeholder Pensions successful. Some offices expect to need to reduce costs by up to 70 per cent to meet the basic cost targets. One cost on which the spotlight has fallen is commission paid to the intermediary, sales force or channel partner. In the 
Q How much, if any, does your pension provider charge you for managing our money?

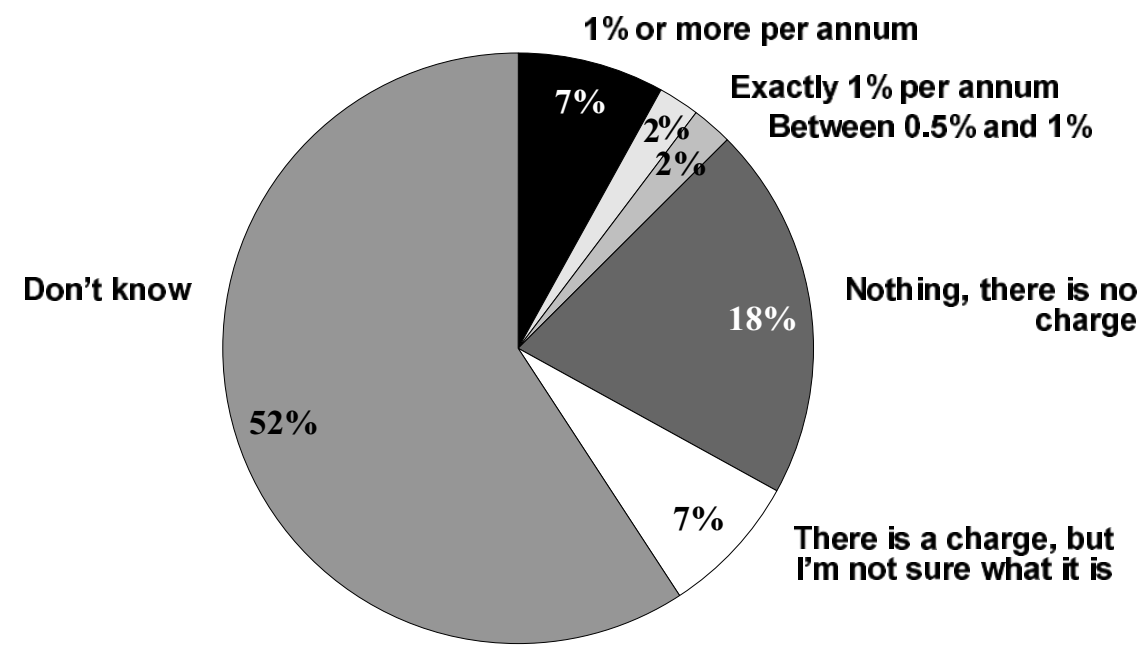

Figure 3: Awareness of charges If charges were set at $1 \%$, would you pay a higher charge if
there was a higher rate of return?

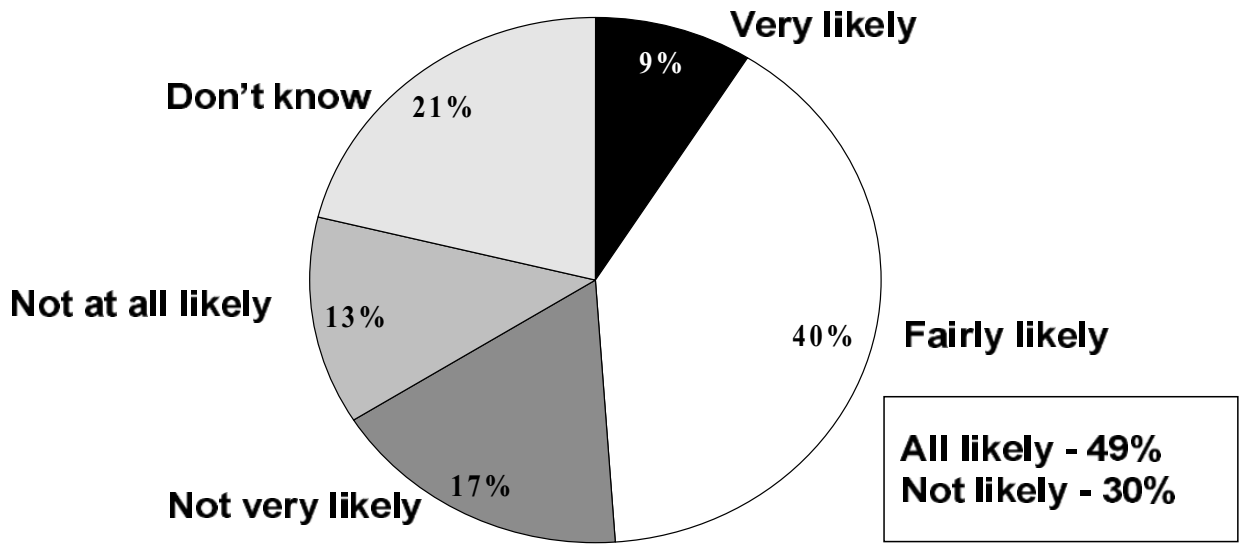

Figure 4: Willingness to pay charges

years 2000-2001, many offices analysed their costs in this area and as a result most rejected the Direct Sales Force option. This led to the problem for some offices that distribution commanded a premium. The IFA channel currently has the lion's share, and in these circumstances competition for distribution may drive up commission levels.
Government strategy has left consumers in the lurch, as those targeted with these low-cost products are the very consumers who need quality advice to manage apparently unrealistic expectations, and to educate them in the need for long-term savings. The advent of the 1 per cent charge cap will not allow for the providers, or the distribution channels, to provide the 
Q Would you be prepared to pay additional charges of up to $\frac{1}{2} \%$ p.a. to cover the cost of you receiving professional advice on finding the right product and managing it in the future?

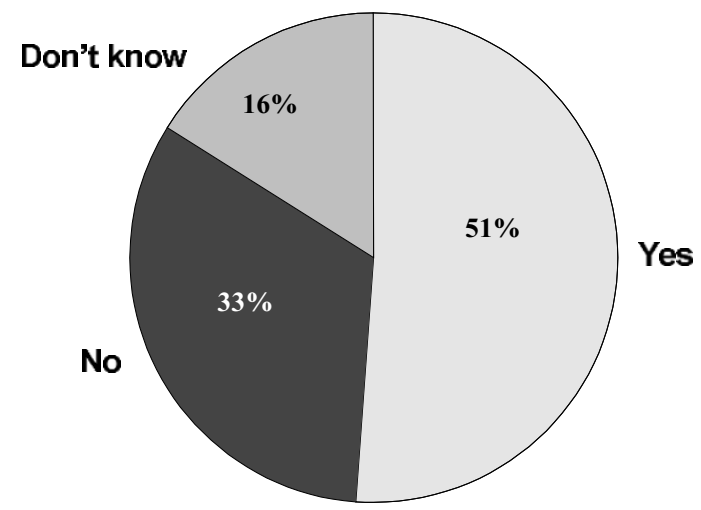

Figure 5: Willingness to pay additional charges for advice

\section{Lower income are more concerned with \\ 'above average' products}

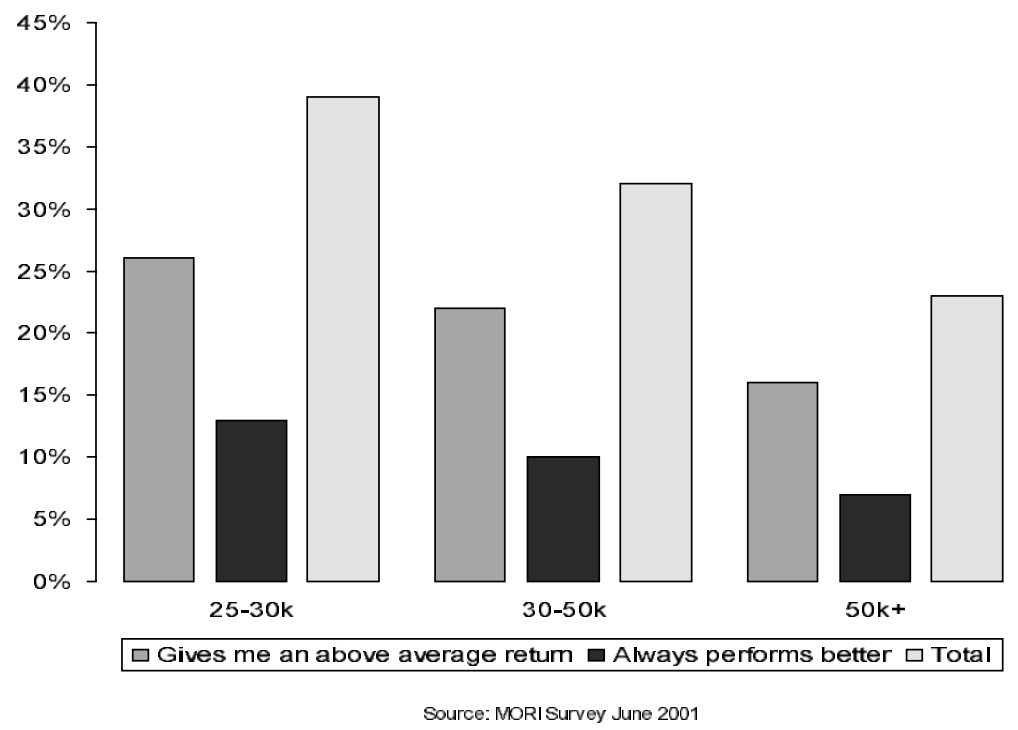

Figure 6: Variation in responses by income

luxury of advice funded through commissions, so fees are the only realistic way forward, except that they need to be levied on consumers who can least afford to pay.

The FSA has recognised this in a limited way in the proposals presented in CP121. There are two suggested approaches - first of all the 1 per cent may well not include the commission charge, as IFAs will be required to go down a fee-based path. In addition, for those consumers for whom the Stakeholder Pension was 
meant to close the $f_{27 b n}$ UK savings gap, the FSA recommends a 'pro bono' approach where IFAs offer their services through local Citizens Advice Bureaux. We seriously question the ability of the remaining IFAs who will be fee-based to find any margin left to be able to support any form of "pro bono' activities.

The conundrum faced here is very real. Even for those in the target marketplace, a Stakeholder Pension may not be the best option for the consumer. Without appropriate advice, a consumer may be worse off. Alison Steed of the Daily Telegraph observed, 'For example, a 25-year-old saving 100 a month and hoping to retire at 65 would find that Standard Life - Europe's biggest mutual insurer - provided the cheapest pension with its Personal Pension One plan. This plan, if you invested in the with-profits fund, would cost you $£ 28,920$ in management charges during the 40-year life of the contract. Another surprise is that Standard Life's cheapest pension costs almost half as much as its stakeholder plan. So, even after the introduction of "cheap and cheerful" stakeholders, choosing a pension remains a complex task to be approached with care. You even need to consider how you buy the product to make sure that you are not paying unnecessary fees.' ${ }^{2}$

At least two Life Offices have aimed to dominate provision of Stakeholder Pensions so as to achieve economies of scale. In other markets, commoditisation of products can lead to fewer 'manufacturers' even if there are multiple branded products in the market.

Detergent is a prime example of this. In the US the $401 \mathrm{k}$ provision has led to one fund manager taking the majority of funds, and another provider taking the majority of product servicing. Both organisations do not see $401 \mathrm{k}$ as a source of profit. However, the relationship with the consumer that the product enables leads to other more profitable products being cross-sold.

In the UK the distribution of regulated products remains highly fragmented (see Figure 7), with much expense in the value chain. Again in the USA, increased consumer awareness, and a more mature marketplace has seen a shift in provider marketplace, with disintermediation occurring at all levels. This is evidenced by the rise of direct investment in Mutual Funds and in the higher level of personal share ownership. The consumer in the UK has some way to go to reach this level of financial awareness.

To succeed in the 1 per cent world a Life Office needs to make a number of choices. If it is to remain a 1 per cent product manufacturer then:

- back office costs need to be radically reduced

- straight through processing needs to be enabled through investment in technology

- distribution friction needs to be removed from the value chain

- critical mass needs to be achieved

- cross-selling of products must be enabled either directly, or by working with chosen channel partners.

In terms of the back office a number of expense areas must be restructured (see Figure 8).

Providers that cannot achieve low-cost goals will need to exit from manufacturing. This pressure, combined with the pressure on access to distribution that depolarisation may be bring will lead to a rapid consolidation of the life industry into a significantly smaller number of players than today. For the consumer, 1 per cent may lead to a reduction in the provision of quality financial support. The products may not 


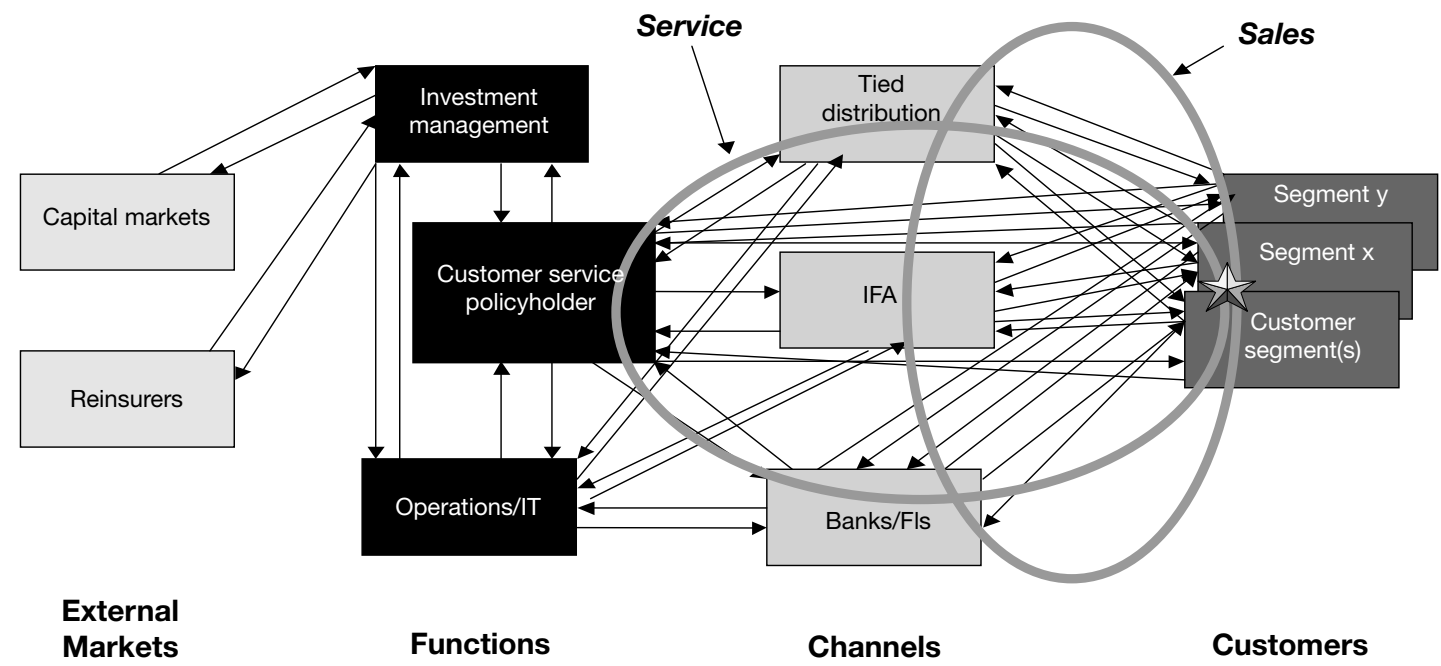

Figure 7: Distribution of regulated products in the UK

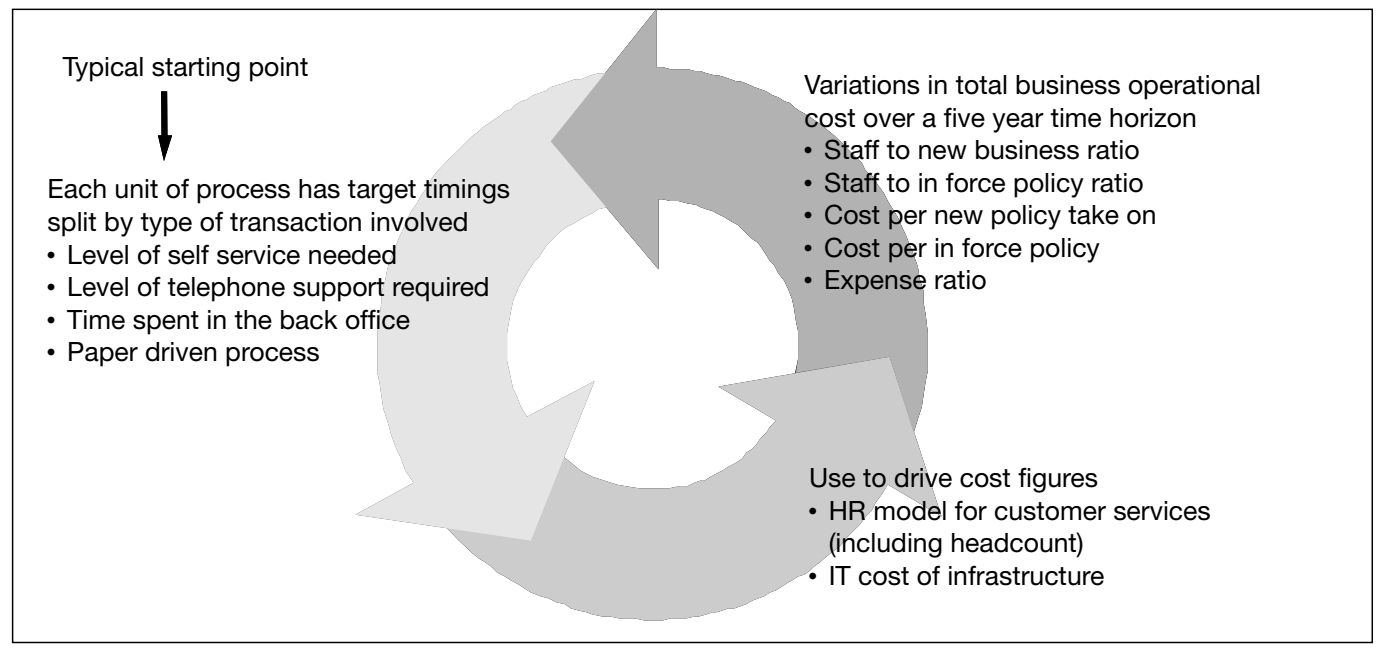

Figure 8: Expense areas needing restructure

be the best and consumers may be prevented from obtaining the advice that they need.

\section{Alliance management}

Research IBM has done into alliance management by insurance providers has some interesting and relevant headlines for the UK:

(1) A provider's use of alliances is positively correlated to value creation

(2) Providers are entering into alliances for three primary reasons

- Revenue growth

- Expense optimisation and reduction

- Strategic positioning

(3) Alliance formation is growing at an increasing rate, both globally and in the UK

(4) The value from alliances in the insurance industry is expected to grow significantly 


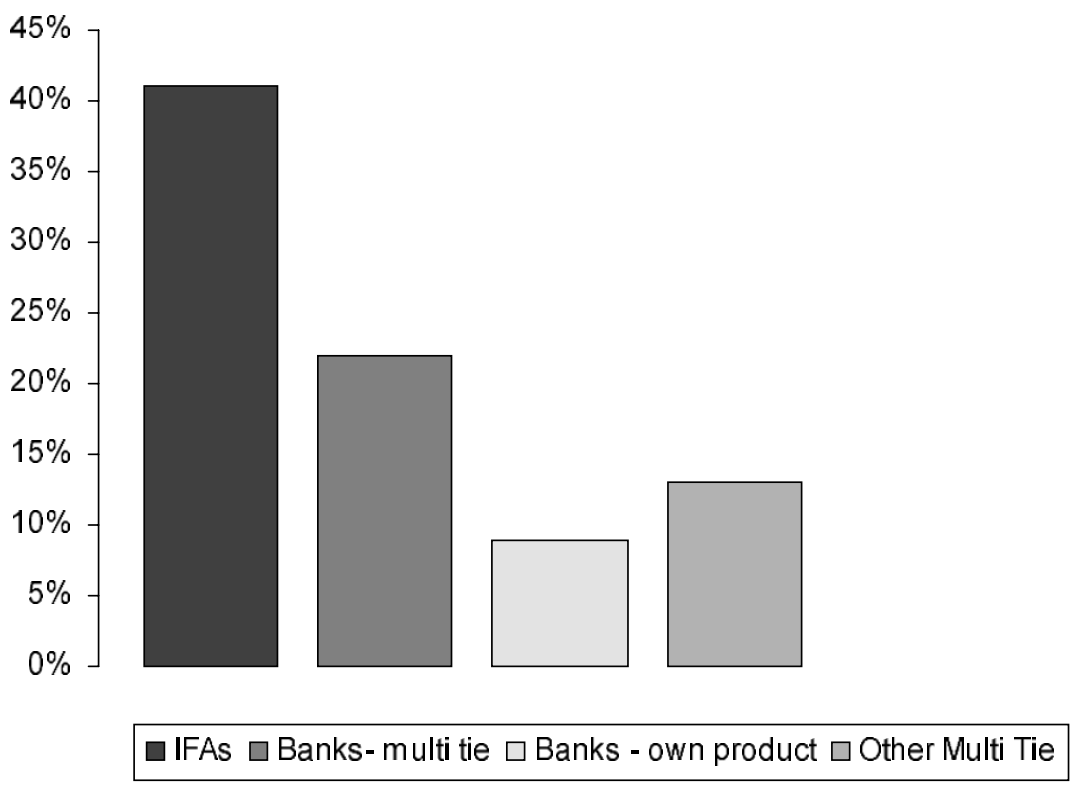

Figure 9: Propensity to use different channels

\section{Depolarisation}

The first stage of depolarisation - in which intermediaries formerly obliged to recommend the best product from all suppliers or to align themselves 100 per cent with one supplier can select a limited number of manufacturers with whom to deal - has already occurred with the advent of Stakeholder Pensions. Life Offices can resell Stakeholder products of other organizations. CP121 has now been released and raises some interesting issues. At first the reaction was one of horror for incumbent IFAs; however, as the dust begins to settle it may not be so revolutionary after all.

What is more interesting is that the 'commission bias' has been allowed to remain in place for multi-ties, although so will the 'benefit-in-kind' rule. It is hard to see the latter surviving as large organisations will not let it get in the way of forming tightly integrated tri-partite relationships between their panels of providers and their large and attractive customer base. What CP121 does indicate that is that the banks will be well positioned, 'benefit in kind' recommendations notwithstanding.

The next stage of depolarisation may have a much greater impact on the market. Full depolarisation may enable distributors to have multiple ties with life offices. In some cases this just recognises current practice - the panel approach taken by many IFAs. However, it will enable banks to have multiple ties with life offices and to offer a choice of brand-leading life products. The research by FTRC and MORI tells us that consumers will be more open to this approach. It seems that this propensity to use banks offering a choice of products may be at the expense of IFAs. Figure 9 shows the propensity to buy from:

- IFA offering independent advice on a range of products in the market

- banks offering products it has selected as best

- banks offering their own products

- other channels.

IFAs are biding their time, waiting to see 
what the model of depolarisation will be. The challenge that IFAs face in their battle with the banks will be relative lack of capital to develop propositions and brand in the marketplace. Pauline Stoffberg wrote in Money Marketing ${ }^{3}$ with some advice for IFAs considering their future, 'Are the majority of your clients high-net-worth or mass-affluent? Are they largely corporate? Do you rely heavily on professional introducers? Do you or your clients value your independence beyond anything else? Can your business survive without external support? Do your life and pension sales follow on the back of your mortgage or general insurance work? If your answer to any of the first four questions is yes, then far from considering multi-ties, your energies would best be deployed joining an organisation lobbying regulators, the Treasury and providers ... But if you answer no to the first four and yes to five and six, multi-ties may afford you improved support.'

Some Life Offices have recognised this and are considering a strategy of taking minority stakes in IFAs, first of all to enable the IFAs to invest and develop their business, but more importantly to protect a key channel of distribution. For the smaller Life Offices this will create a tremendous challenge. IFA panel sizes have already shrunk significantly, with quality providers being more likely to survive. This will be mirrored if the model of depolarisation introduced leads to 'bancassurance' growth. The net result of these changes will be that the top four or five Life Offices will develop a tighter grip on both product provision and access to distribution.

For the consumer, depolarisation may well be a step forward. Despite protestations from the Association of Independent Financial Advisers that the consumer is very aware of the advantages of polarisation, our research indicates that most consumers (other than the most important customers of IFAs) are not aware. The majority of consumers, those the Government is trying to target with products such as ISAs and Stakeholder Pensions, are not clear about the role of the IFA, or the cost that they pay an IFA for advice. The potential advantage to the consumer in a depolarised world is that tied salesmen have typically met Government targets for charge-capped products in the past. Although many of these salesforces are now gone, access to a choice of quality products through multi-tied intermediaries, such as a bank, may well be a step in the right direction.

\section{Rationalisation}

The combined effect of the low-cost operating environment and depolarisation squeezing out competition for

distribution may be acceleration of rationalisation in the Life Industry. This has already been an area of great activity in the UK, but there is still some way to go. There is simply not a good enough return on equity to support the forty or so stakeholder manufacturers. Those not absorbed may move to a different business model of reseller of others products. The remainder are likely to move into niche plays, if they survive at all.

One concern is that those seeking a good return on capital will not find the UK Life Industry an attractive place to invest. This will also be a challenge for UK-based offices that want to expand abroad, especially into Europe. The reduction in returns, and the restructuring for the leaner market in the medium term in the UK market will be a drain on capital that will slow down expansion abroad. Also the failure of Government and the FSA to prevent the problems seen at Independent Insurance and Equitable Life will lead to a question 
mark in overseas markets over the capability of British Insurers to operate successfully. It is therefore possible that Government will intervene yet again, with cost pressures and technology forcing more consolidation, this time on pan-European or even global. It is unlikely that, British firms will benefit.

\section{Effective IFA distribution}

For several years Life Offices have recognised the benefits of creating a more effective, automated link between themselves and the multitude of IFAs in the market. The IFAs come in many forms and so the creation of some form of Common Trading Platform is of increasing interest. In recent years two strategies have emerged. The Exchange which provides a basic common trading platform is the most widely used to obtain quotes. However, the service is basic and once a quote is obtained the IFA then has to resort to contacting the Life Office directly to transact new business. This is not in line with cost-reduction through straight through processing!

The second strategy of Life Offices is to launch Extranets offering increasingly sophisticated servicing and work-tracking services. The majority of the larger IFA firms now regularly use these Extranets. However, the IFAs were generally frustrated with the services offered. This is because each Extranet is proprietary, so for an IFA or IFA administrator working with several providers must log in separately to each Extranet, and learn how to navigate on each site. IFAs are frustrated by this, particularly those who themselves have invested in eCommerce and cannot easily integrate their own systems with those of the providers. IFAs report that they find providers frustrating to deal with as they generally do not show much interest in working with
IFAs to learn how to better work together. Providers typically develop Extranets to meet their own needs, rather than those of the marketplace or specific IFAs. A small number of providers have carried out 'clinics' with small numbers of IFAs, to work together on joint propositions. However, this is not the norm. The development of eCommerce solutions will continue to be thwarted unless this barrier is resolved.

On a more positive note, several providers are developing more sophisticated web services that enhance an IFA's offering. Skandia's

MyMultiManager is a service that can be embedded in the IFAs own website, offering a full service fund supermarket. The offering creates a servicing capability for the IFA to assist with portfolio management, which in their own words provides:

- sophisticated portfolio tools to build and manage model portfolios and rebalance those portfolios

- total view of clients, enabling valuing and bulk switching all Skandia investments as one

- data download service to help in servicing clients

- on-line applications for many investment and pension contracts, through different tax wrappers - unparalleled range of multi-manager funds across the Skandia platform.

Similar offerings are being brought to the market, for example Selestia from Old Mutual, offering IFAs a portfolio management service. Another provider has created a policy servicing capability that can be embedded to enable consumers to service their policy through their IFAs website. There is a big opportunity to use this approach to get the industry to move to 1 per cent world and effective, efficient distribution. 
However, fragmentation of the market — both IFAs and providers - creates a big barrier to progress. The creation of offerings such as MyMultiManager is a big step forward for the IFAs. However, it may accelerate what has been seen in other markets eg the switch to direct investment in mutual funds, away from long-term savings products.

\section{Direct}

The direct telephone-based approach has been successful for some products, typically high margin, or simple, execution-only commodities, for example Guaranteed Term Plans or ISAs and Bonds. Providers that have tried to sell complex products such as pensions have struggled to make such offers compelling. The focused fact-find approach has made the task a little easier, but consumers are unwilling to spend a long time on the telephone, and in many cases do not have the information to hand needed to complete the transaction. Some larger IFAs have been successful in running off-the-page direct marketing activities, with direct fulfilment via call centres. These operations run with a very low ratio of registered individuals to cover key client questions or more complex transactions. For the moment, an approach via direct channels such as the telephone in support of direct marketing activity will remain profitable in only a few product areas.

\section{Alternative market access - Worksite marketing; channel of opportunity?}

The selling of financial products through the workplace is not new. Many companies offer pension, health and other products and services through workplace schemes. However, the landscape is changing as the boundaries between work, play and home begin to blur, driven by changing consumer demand and new technological capability. Employers are looking for more innovative, flexible and affordable benefits provision while employees want choice and convenience. Today what they both often get is disjointed, inflexible, labour-intensive benefits provision. Many industry players provide some of the answer but it appears that none can do it all. What organisations need is a 'solution integrator', a provider who can consolidate various products and services into a single proposition, through a single interface, which attracts and keeps its most valued employees working for them.

Worksite marketing is receiving increasing attention from providers seeking to exploit low-cost alternative distribution options in the battle to grow and keep market share. Providers with existing worksite operations are considering how technology can differentiate them and drive higher penetration rates. Rapid advances in network and mobile technologies continue to give the consumer more choice on how and where they buy financial services products, at home or at work, extending the reach of the traditional worksite market.

The USA worksite market has matured and the growth in worksite sales of financial products has beaten growth in traditional sales by a factor of four during the 1990s. There are similarities in worksite dynamics between the US and UK markets, most notably in the areas of pension reforms and the increasing consumer adoption of e-commerce. This suggests that rapid growth in the worksite distribution channel is set to occur in the UK. The introduction of Stakeholder Pensions has encouraged increased worksite activity, if not full-blown worksite marketing. 
Several providers have worksite offers, and employers have retained IFAs for fee-based advice, with fees paid by the employer on behalf of employees. This approach may accelerate the acceptance of a more integrated worksite offering.

Although technology can be a key enabler of worksite with products and advice being offered through Intranets, a barrier to this is the expense of creating integrated payroll and human resource systems. This is vital in creating straight-through processing, which significantly reduces the cost of scheme and product administration, as the employer carries out much of the employee administration. A leading provider of $401 \mathrm{k}$ in the USA has invested heavily in establishing this integration. This has enabled it to 'break even' for core product provision. The provider now has the advantage of a direct link to its customer base and is now increasing its revenues and profits through low-cost cross-selling.

From an employer's perspective, a key proposition that will help embed the worksite offer will be the introduction of 'cafeteria benefits', where employees take responsibility for selecting their own balance of benefits, perhaps trading holiday or car allowances for better life cover or pensions provision. This highlights one of the key elements of ensuring that the worksite offering is successful. As it is with the market at large, any large employer will have employees with widely differing needs, from executives to blue collar workers. Segmentation of treatment, proposition, advice and products is an important dimension for any worksite scheme.

\section{Integrated multi-channel distribution}

Historically, the Life Offices have typically been dependent on a single main channel to market, Allied Dunbar with its sales force, Standard Life and its dominance of the IFA channel being two examples. The number of channels has been condensed even more recently. Many offices that had a secondary or even primary channel based on the sales force have seen the economics of this channel look weak and the majority of salesforces have been dropped. However, some providers have achieved greater productivity through integrating several channels into a single combined proposition. An approach such as this will use web services to provide product information and advice on financial management, call centres to coordinate customer activities and sales to execute transactions. Organisations taking this approach have successfully driven greater sales productivity.

A similar model may well emerge for intermediaries. Some life offices already provide additional marketing and database analysis services to IFAs for renewals and life stage events. In the future, a multi-tied intermediary will allow (assuming no infringement of benefit in kind regulations) a more significant 'tri-partite' relationship to be formed - with the intermediary and the provider working in collaboration to drive value from the customer base. This will improve yield management of the customer base, something that the life industry has not done well in the past.

\section{Regulation}

It would be impossible to write about the life and pensions marketplace without a word on regulation. Regulation has placed a huge burden on the industry both in terms of actual cost and opportunity. Regulation that has focused on the point of sale has, not surprisingly, increased the cost of sale. The cost of implementing 
regulation is great - scarcely a year has gone by without some mandatory change to the sales process, reducing the ability of Life Offices to invest in infrastructure and propositions for tomorrow. Regulation has usually been applied mainly to fix problems retrospectively eg mis-sold pensions. The regulator has fared less well in creating positive solutions to help companies and consumers manage risk. A more forward-looking approach might have identified the problems at Equitable Life or Independent Insurance. However, there has been a shift over the past two or three years from point of sale regulation to product regulation, with the introduction CAT-marked products. Still, the future of regulation for the Industry still remains bleak as the FSA now has new-found teeth and is looking closely at the industry again, to ensure that it is not caught out as it has been over the past couple of years. There will be a significant increase in personal accountability for Life Office executives, although it is not certain where this will lead. However, it is clear that regulation of the financial services industry as a whole will increase. An example of potential worry for the Life industry is CP98, which explores making mortgage providers responsible for all sales compliance, irrespective of the channel. If this principle were applied in Life, it would significantly change the landscape of the Life sector, which is currently increasingly dependent on IFAs who carry the burden of compliance today.

The FSA may be pressured to control rather than empower the industry. It is also evident that there are key stakeholders beyond the FSA such as Treasury, which has different interests. To deal with this potentially disruptive situation, we believe the Life Offices should join forces to lobby Government and its agencies effectively.

\section{Know where you are}

As a Life Office this is a time for strategic choices. Many offices have already begun to make choices, with Standard Life focusing on being a mutual product manufacturer, Norwich Union focusing on market dominance, especially for Stakeholder Pensions, Legal and General developing a multi-channel approach including IFA, Bancassurance and Direct.

The first step in making these strategic choices lies with an exploration of the core competencies of the organisation.

- Customer centric: Organisations that have a strong relationship with customers should focus on enhancing their relationships to get further value from these relationships and increase the share of wallet. Few life and pensions companies are truly customer centric

- Production centric: Many large life and pensions organisations believe that their real strengths lie in production, with the large-scale operation of product factories. This is because of the intermediated nature of the life and pensions marketplace. The exemplar of a production-centric business in the insurance sector is Direct Line, which has demonstrated that effective and efficient operation of scale can result in an operating ratio of nearly half the sector average. What remains to be seen in the life sector is whether large players can emulate this production focus and reduce cost ratios by the required 50-70 per cent.

- Fulfilment centric: Several life providers are not manufacturers and are focusing on creating leading edge 


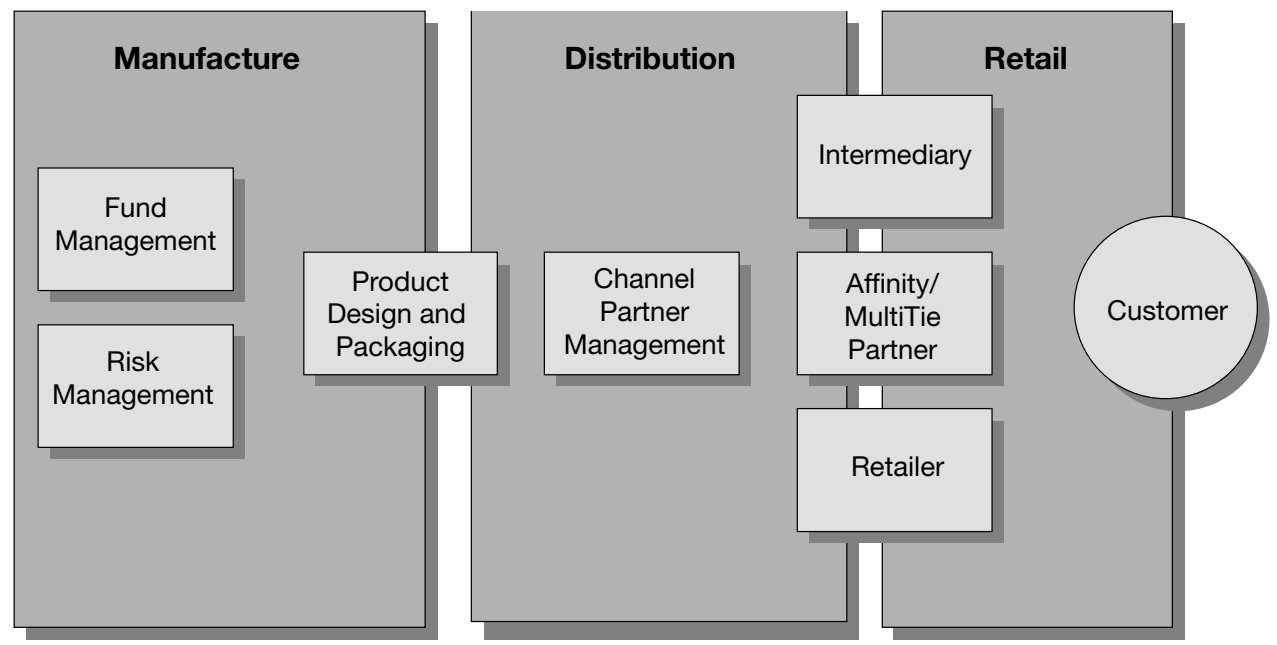

Figure 10: Roles in insurance value chain

fulfilment models, specifically in the IFA arena eg Skandia's

mymultimanager.com that enables an IFA to provide a fund supermarket service to their customers, as well as providing portfolio management services for the IFAs themselves.

Selestia.com optimises the delivery of services and products to the client from a range of providers. The focus is on optimising the fulfilment and service to the end consumer, in addition to providing the IFA with a strengthened service proposition.

- Marketplace centric: There are several marketplace centric offerings in the life and pensions sector. However, these are not core businesses, but typically small-scale service providers. A key problem with this model is the ability to charge for the services offered. A number of reinsurers have marketplace centric offerings running alongside a production centric model.

\section{Strategic evaluation}

Life offices must now reassess their position in the marketplace, specifically their role in the value chain (see Figure 10) investing and developing the core competencies outlined above. The key areas are production, distribution and retail. In our view, few players have the brand and infrastructure to be truly retail-oriented. This may pave the way for more significant partnerships emerging, with logic, if not history seeing banks at the top of the list. The remaining options are Distribution to channel partners (the Skandia approach), or low cost manufacture (eg Fidelity).

\section{References}

1 Anthony Hilton (2001) Evening Standard, London, 2nd August.

2 The Daily Telegraph (2001) "Cheap And Cheerful" Might Not Be Such A Bargain After All: A New League Table Has Some Surprises On The Relative Costs Of Stakeholders', Alison Steed Reports, 24th November.

3 Money Marketing (2001) 22nd November. 